\title{
THE ACCRETION MODEL OF NEANDERTAL EVOLUTION
}

\author{
John D. HawKs*,1 AND Milford H. WolpofF*,2 \\ ${ }^{1}$ Department of Anthropology, University of Utah, Salt Lake City, Utah 84112-0060 \\ E-mail: john.hawks@anthro.utah.edu \\ ${ }^{2}$ Paleoanthropology Laboratory, Department of Anthropology, University of Michigan, Ann Arbor, Michigan 48109-1382 \\ E-mail: wolpoff@umich.edu
}

\begin{abstract}
The Accretion model of Neandertal evolution specifies that this group of Late Pleistocene hominids evolved in partial or complete genetic isolation from the rest of humanity through the gradual accumulation of distinctive morphological traits in European populations. As they became more common, these traits also became less variable, according to those workers who developed the model. Its supporters propose that genetic drift caused this evolution, resulting from an initial small European population size and either complete isolation or drastic reduction in gene flow between this deme and contemporary human populations elsewhere. Here, we test an evolutionary model of gene flow between regions against fossil data from the European population of the Middle and Late Pleistocene. The results of the analysis clearly show that the European population was not significantly divergent from its contemporaries, even in a subset of traits chosen to show the maximum differences between Europeans and other populations. The pattern of changes, over time within Europe of the traits in this subset, does not support the Accretion model, either because the characters did not change in the manner specified by the model or because the characters did not change at all. From these data, we can conclude that special phenomena such as near-complete isolation of the European population during the Pleistocene are not required to explain the pattern of evolution in this region.
\end{abstract}

Key words.-Accretion, gene flow, genetic drift, Neandertal, selection.

Received August 16, 2000.

The Neandertals were the Late Pleistocene human populations living in Europe and parts of Western Asia until approximately 30,000 years ago, more or less. It has long been observed that this hominid group was morphologically different from its contemporaries and from later human populations. In several recent papers, a new theory, called "Accretion," has been proposed to describe and account for the evolution of the European Neandertals. In articulating the Accretion model, Hublin (1998, p. 307) noted:

Since [450,000 B.P.], the European hominids display the development of derived morphological features relating all the known specimens to a unique lineage leading to the Neandertals. This evolution resulted from an accretion process characterized by the successive occurrence of new features and by an increase in their frequency within the pre-Neandertal populations.

All authors do not agree that the Neandertal features are new, but there is concurrence that they change in frequency during the Middle Pleistocene.

[The] greater complexity in the patterns of Middle Pleistocene human evolution ... supports the view that the accretion of Neanderthal features might result in a shift in the frequency of the derived conditions rather than from the clear cut emergence of new morphologies (Stringer and Hublin 1999, p. 876).

How did this happen? Hublin (1998, p. 307) notes:

The peak of stage 12 (425-480 ky BP) ... may have caused a significant demographic crash in the European populations and triggered their evolutionary divergence. Added to the founder effect following the initial colonization of Europe by small populations, such events

*The authors contributed equally to this paper.
Accepted March 5, 2001.

would have produced genetic drift episodes resulting in the fixation of derived features. In this view, some of these features could have developed although they do not have a clear adaptive significance. This model would predict a decrease of the variability ... in the pre-Neandertal/Neandertal populations that experienced major changes of their size

Similarly, in a study of nasal variation, Maureille and Houet (1998) suggest that the level of metric variation in the isolated Neandertal population should be low compared to a nonisolated population because of the effect of genetic drift.

Two things are apparent from the quotations provided above. At one level, the Accretion model is no more than a hypothesis of pattern: morphological features in the European Middle and Late Pleistocene appear, at least to some researchers, to "accrete" over time. This usage is essentially a restatement of mosaic evolution. For this reason, the Accretion model entails a hypothesis of process: accretion in features in this particular geographically defined group over time is due, according to some researchers, to evolution by genetic drift, caused by the partial or complete isolation of this lineage. As Dean et al. (1998, p. 505) commented, “The primary conclusion one draws from the Accretion model is that gene flow into Europe was restricted from the middle Middle Pleistocene well into the Late Pleistocene." Other researchers take an even stronger position, such as Hublin (2000, p. 163) who writes, "More probably, European and African populations remained isolated for most of the last half million years."

In this paper, we provide a test of the Accretion model, based on the expected phenotypic divergence of populations connected by gene flow. This perspective has been lacking in previous analyses, which depend on the observation of "distinctive" characteristics without making explicit explanations of what such "distinctiveness" actually means. Met- 
ric data from fossil Europeans and non-Europeans reflects the phenotypic divergence of these populations, and we test these data from traits that have been suggested to be "distinctive"' among ancient Europeans to evaluate whether they refute a null hypothesis of interregional gene flow. Our results indicate that no model of isolation is required to explain the pattern of European metric data, and these data fail to indicate an accretion of features over time in the European population of the Middle and Late Pleistocene.

\section{Testing Gene Flow}

It was Howell (1952) who first systematically addressed the issue of interregional gene flow among ancient humans, assessing divergent evolutionary trends in the Western European Neandertals (then thought to be) dated to the last glaciation and attributing these divergent trends to the effects of isolation caused by the glaciation itself. But the Accretion model requires that this isolation extend over much of the Middle and Late Pleistocene, a much longer time period over which there are no geographic, climatic, or other factors that would appear to present barriers to gene flow to and from Europe for all or most of the relevent time span. Instead we may expect that Pleistocene glaciations, which periodically reduced the habitable land area of Europe by as much as twothirds, resulted in a large amount of gene flow into and out of Europe as people tracked habitable zones and encountered populations in adjacent regions. This tracking has been one explanation for certain morphological similarities between Europeans and some West Asians of the Late Pleistocene. Indeed, the only possible source of isolation during this entire time period would seem to be simple geographic distance, which would imply some limit on the rate of gene flow, but not an absolute one. These factors argue that we cannot assume the complete isolation of European hominids, without first subjecting the hypothesis of gene flow to an appropriate test. A null hypothesis with respect to gene flow is then that the European population was connected to others in a pattern of isolation-by-distance. Within this framework, the specific level of gene flow may be unknown, but if a test fails to reject a particular level of gene flow, we will have no particular reason to believe that it did not occur.

As noted in the introduction, several researchers have indicated that the level of morphological distinctiveness of Pleistocene Europeans implies that the level of gene flow between this population and its contemporaries was very low or nonexistent. Historically, researchers have considered discrete traits among Pleistocene Europeans to be "distinctive", if they occur at low-though usually unspecified-frequencies in other human populations. Indeed, in light of the fact that no external isolating mechanism is apparent between Europe and other regions, some researchers have posited that these "distinctive" morphological features themselves caused isolation of the European population, by interfering with mate recognition among contemporary hominids. But as noted above, there is no nonmorphological reason to suspect very strong isolation of Pleistocene Europeans, and claims of isolation based on morphology have without exception been made without any formal test of either the frequencies of traits or their significance.
Although we agree that traits are sufficient to form a hypothesis of some limitation on the level of gene flow, they have not yet provided a test of a gene flow hypothesis (Løfsvold 1988). What we need is some information about the probability distribution from which the distinctive traits of Pleistocene Europeans are drawn. Any random collection of traits, especially in a small sample, will contain some apparently "distinctive" characters whose frequencies are different among predefined groups. As we examine the small set of specimens more carefully, it is inevitable that we will find more such traits, or worse, that we will find many correlated traits and count them as independent ones. For Pleistocene Europeans, no one has yet tried to count the number or proportion of morphological features that are not distinctive. Because the number of such traits that we might have examined-but did not-is potentially very large, we cannot even arrive at an estimate of how "distinctive" the European population might have been, much less any estimate of the rate of gene flow. This is because even though we could choose to take observations on a large set of additional, nondistinctive features, there is nothing to tell us just how large a set we should choose, making any estimate of proportion meaningless. Further, for each additional character that we added, we would need estimates of its covariances with the other characters, but such estimates will have little accuracy on the limited set of fossil specimens available to us. Clearly for these reasons, no accurate picture of the distribution of distinctiveness in traits can be available to us.

Some have suggested that if Europeans were isolated during the Pleistocene, then we should expect to find that the population should have a low level of metric variability (Dean et al. 1998; Hublin 1998; Maureille and Houet 1998). But in general it is not true that a reduced level of genetic variation, whatever the cause, leads to a reduced level of phenotypic variation of metric characters (Falconer and Mackay 1996). This is often because an inbred population with less genetic variation usually will exhibit increased nongenetic variance. For this reason and for the reason of small sample sizes, we cannot feel confident about any assessment of the level of gene flow based only on the within-European level of phenotypic variation.

A distribution that is available to us is the distribution of how much phenotypic difference should exist among subpopulations connected by gene flow. In other words, although we do not know what proportion of traits among Pleistocene Europeans are divergent, we do know how divergent some "distinctive"' traits are. We can use this distribution to test whether the level of phenotypic "distinctiveness", of those traits is surprising under the null hypothesis of gene flow. This distribution is model-specific, which means that we must specify an evolutionary model and from it derive the expected distribution of morphological change.

Such an analysis will allow the comparison of traits known to be 'distinctive," to whatever degree, to a relevant probability distribution describing the level of difference that should exist between a subpopulation and the total population under the hypothesis of gene flow. It is important to note that this method does not allow an estimate of the level of gene flow. We intend to test a null hypothesis that an equilibrium level of gene flow connected the European human population 
with the rest of the world during the period from roughly 500,000 to 40,000 years ago. If the available data do not reject this hypothesis, then we must conclude that the distribution of skeletal traits in Pleistocene European populations is not unusual under a model of isolation-by-distance, and there is no need to posit extraordinary isolating factors, including speciation, to account for their evolution.

\section{Evolutionary Model}

Intuitively, it would seem that a greater level of isolation would cause a greater level of phenotypic divergence of subpopulations, which is the basic assumption of the Accretion model. However, in order to derive the distribution of phenotypic divergence, we will need to consider the genetic and nongenetic factors that cause phenotypic change to occur. These include two primary genetic causes-natural selection and genetic drift. They also include two primary nongenetic causes-changes in environmental variance and interaction variance. There is no consensus on the importance of any of these forces on any of the characters that we might observe in Pleistocene Europeans, and we cannot consider any of them to be a priori a more likely source of change. However, we are primarily interested in whether gene flow may be excluded by morphological data. The major weakness in examining this question is that under certain regimes of selection or changes in environment, no test of gene flow may be possible. For this reason, we first outline the conditions that may lead to significant change within the European population even if gene flow from other regions was always present.

The most obvious possible source of change over time in this population is selection. We cannot reject, and do not attempt to reject, the possibility that selection has exerted a primary influence on the pattern of morphological variation of Pleistocene Europeans. For many of the "distinctive"' features found in this population, realistic selective regimes may be imagined that would have changed the distribution of phenotypic values in the observed way. Indeed, illuminating these selective explanations has been a primary goal of evolutionary research on this group (Trinkaus 1992). Selection concerns us here primarily because if we find any unusual level of interpopulation difference in the phenotypic value of a trait, it may be the result of selection and not of restricted gene flow. This is a significant problem for the researcher attempting to confirm a hypothesis of isolation, because to refute gene flow with selection she or he would first have to refute every possible selective mechanism that may apply to the traits examined, which is the primary criticism that has been leveled at studies attempting to demonstrate European isolation from morphological characters. In the following, we attempt to test the hypothesis of gene flow without selection, leaving the consideration of selection to the discussion.

Other factors that may cause significant phenotypic change within the European population over time include changes in the environmental component of variance $\left(V_{E}\right)$, presence of a significant interaction variance $\left(V_{I}\right)$, and changes in the mutational variance $\left(V_{M}\right)$. Of these factors, the least important is the last, because the mutation rate among coding loci is unlikely to have varied enough among human populations over the course of the past 400,000 years to cause a large difference in either the rate of phenotypic change or the level of phenotypic variance. Differences in $V_{E}$ and $V_{I}$ are more difficult to dismiss, both because of the unique character of the European environment compared to other regions during large stretches of the Middle and Late Pleistocene and because of the often rapid climatic changes that characterized this period of time. The actions of either of these factors are formally similar to selection, in that either of them may cause significant phenotypic divergence of populations even in the presence of gene flow. Like selection, $V_{E}$ and $V_{I}$ have been suggested as primary influences on morphological change in Pleistocene Europeans, although the persistence of particular phenotypic values for traits in vastly different climatic regimes partially belies such assertions. Nevertheless, we consider these factors in the same class as selection in their potential effects on phenotypic traits, and as in the case of selection, we attempt to refute a model in which they are assumed to have no effect. Therefore, the model that we describe here is a neutral model with gene flow between regions in which neither selection nor environmental effects have played any significant role in differentiating regions, keeping in mind the considerable probability that many traits may differentiate Europeans because of these other reasons.

Under this model, the expected genetic differentation of subpopulations is a simple function of the past rate of migration between regions. The actual amount of migration in the past is unknown and probably varied over time. However, an interesting hypothesis to consider is that the genetic differentiation among humans today, with an $F_{\text {ST }}$ between continental regions between 0.10 and 0.15 , was caused by an equilibrium level of gene flow between the same regions in the past. Under this hypothesis, the expected variance in the phenotypic means of groups connected by gene flow is given by Rogers and Harpending (1983, eq. 15) as:

$$
\mathrm{E}\left\{\sigma_{y}^{2}\right\}=2 \sigma_{a}^{2} \frac{R_{0}}{1-R_{0}}
$$

where $\sigma_{y}^{2}$ is the variance in the phenotypic differences of the groups from the centroid, $\sigma_{a}^{2}$ is the within-group additive genetic variance, and $R_{0}$ is simply Wright's (1951) $F_{\mathrm{ST}}$. The within-group additive genetic variance may be estimated as the within-group phenotypic variance, $\sigma_{P}^{2}$, divided by the heritability, $h^{2}$.

In a similar vein, Lande (1979, p. 410) provides a " scaled square of generalized genetic distance'":

$$
\frac{t}{N_{e}} \mathbf{y}^{\mathrm{T}} \overline{\mathbf{G}}^{-1} \mathbf{y}
$$

which is distributed as $\chi^{2}$ with one degree of freedom, where $\mathbf{y}$ is the vector of phenotypic difference of the subpopulation from the centroid, simply $z_{1}-z_{0}$ in the case of a single trait. The scaling factor here, $\left(t / N_{e}\right) \overline{\mathbf{G}}^{-1}$, is the multiplicative inverse of the expected amount of phenotypic diversification of the subpopulation, assuming isolation (Lande 1979, p. 409).

In the case of gene flow, we can substitute the inverse of the right half of equation 1 , above, for the scaling factor in equation 2, obtaining: 


$$
\frac{\left(1-F_{\mathrm{ST}}\right)\left(\bar{z}_{1}-\bar{z}_{0}\right)^{2}}{2 F_{\mathrm{ST}} h^{2} \sigma_{P}^{2}}
$$

as the square of phenotypic difference of the subpopulation from the centroid, scaled to the expectation of that difference under equilibrium migration, and distributed as $\chi^{2}$ with one degree of freedom. For $F_{\mathrm{ST}}=0.15$, this reduces to:

$$
2.83 \times \frac{\left(\bar{z}_{1}-\bar{z}_{0}\right)^{2}}{h^{2} \sigma_{P}^{2}}
$$

We can use this expression to test the null hypothesis of equilibrium gene flow between the European population and the rest of the world duirng the Middle and Late Pleistocene. If our set of "distinctive traits" in fact are markers of evolutionary isolation of this lineage, then the level of morphological divergence of these traits should be very great, compared to the expectation under the hypothesis of gene flow. If none, or very few, of these traits are more divergent than expected under the hypothesis of gene flow, then certainly this hypothesis cannot be refuted by these traits. Therefore, we can compare the level of difference in this subset of traits with the $95 \%$ confidence limit of the $\chi^{2}$ distribution with one degree of freedom. If these traits are not significantly different between the European population and other populations, then these data do not reject the hypothesis of gene flow.

\section{Materials ANd Methods}

Following the categories used by Dean et al. (1998, Table 1), we examined three samples of European hominids to test the Accretion model of founder effect and/or isolation in Europe, especially during the last glaciation (Tables 1-6). Only adults or older juveniles when the morphology is not affected by increased age are used in the tables. Sex is not considered (as it is not in the other studies discussed here) because it cannot be reliably established for most of the fragmentary specimens.

\section{Specimen Selection}

Our selection of specimens and their group affiliations conform to Dean and colleagues (1998), with two exceptions. First, we added specimens such as the Ceprano vault (Ascenzi et al. 1996) and the Apidima crania (Coutselinis et al. 1991) that they did not include. Second, we did not consider any of the Asian specimens discussed in the Dean et al. (1998) and Maureille and Houet (1998) papers, in particular omitting Shanidar, Amud, and Teshik Tash. We regard our examination of the Accretion model as a question of isolation, drift, and independent evolution in Europe; the broader the area encompassed, the less likely that any model of isolation is valid. It was the European Neandertals who presumably were isolated during the last glaciation, and not those from Western Asia. By restricting the problem to a European one, we may more validly examine the possible isolation of Neandertals, and we are being conservative, in that it makes it more likely that the later Neandertals can be shown to have reduced variation, as the Accretion model predicts. The geographic areas represented in our three samples are more or less the same (an exact statement of area is impossible because each com- parison we made incorporates somewhat different sample compositions since all cranial parts are not equally represented).

\section{Sample Selection}

Using the theory described above, it is possible to develop a very precise testing procedure based on the phenotypic values of individual specimens and conditioned on their chronological dates. However, sophisticated approaches using individual dates are of little use to us, because the dates for many of the specimens are very imperfectly known. For example, the earliest large site in our sample, Atapuerca, has estimates of geologic age varying by a factor of two, with a minimum date of 200,000 years ago and a maximum date of some 350,000 years (Parés et al. 2000). In view of the lack of temporal resolution for these specimens, we found it more easily defensible to follow precedent by collapsing the sample into three time segments: pre-Neandertals, early Neandertals, and Würm Neandertals. We chose samples as similar as possible to those that have been presented in support of Accretion, although we did not retain the four-sample division of Dean et al. (1998) because of uncertainties of data that make membership in those two pre-Neandertal groups problematic. The Accretion model stipulates that it is the comparison of pre-Neandertals with Neandertals that is of key importance, and we have retained these groups. Not all the specimens are radiometrically dated and in some cases group membership was determined from geological or stratigraphic considerations. The ages represented for each sample group in Tables 1-6 differ, because the samples differ, but under the assumptions that they all sample the same groups, and that the specimens not directly dated fall within the ranges of the dated specimens for each sample, the three groups more or less extend across 20,000 years (Würm Neandertals), 40,000 years (Early Neandertals), and approximately 200,000 years (Pre-Neandertals). The consequences of the different age spans are reviewed in Table 9. All of the age-related questions are reviewed in Wolpoff (1999) and sources therein.

Tests of the three different time periods may not form independent tests of the hypothesis of gene flow, if the effective size of the population during these time periods was very large, because genetic drift will not equilibrate a very large population during the time spans involved. However, the worldwide effective size has been estimated on the basis of other evidence as less than 20,000 effective individuals (Harpending et al. 1998; Hawks et al. 2000). The effective size within Europe alone is unlikely to have exceeded one tenth of the worldwide amount, and therefore was apparently sufficiently small to allow independent tests of gene flow for the three temporal groups addressed here. A small effective size itself does not address the phylogenetic status of Pleistocene Europeans (Hawks et al. 2000).

Using the groupings presented in Dean et al. (1998), whether or not they are construed to be evolutionary stages, does not imply our acceptance of their validity. We do not necessarily agree with either the groupings or their purported evolutionary meaning. If this grouping does not support the 
TABle 1. Mastoid height from the digastric sulcus (in $\mathrm{mm}$ ).

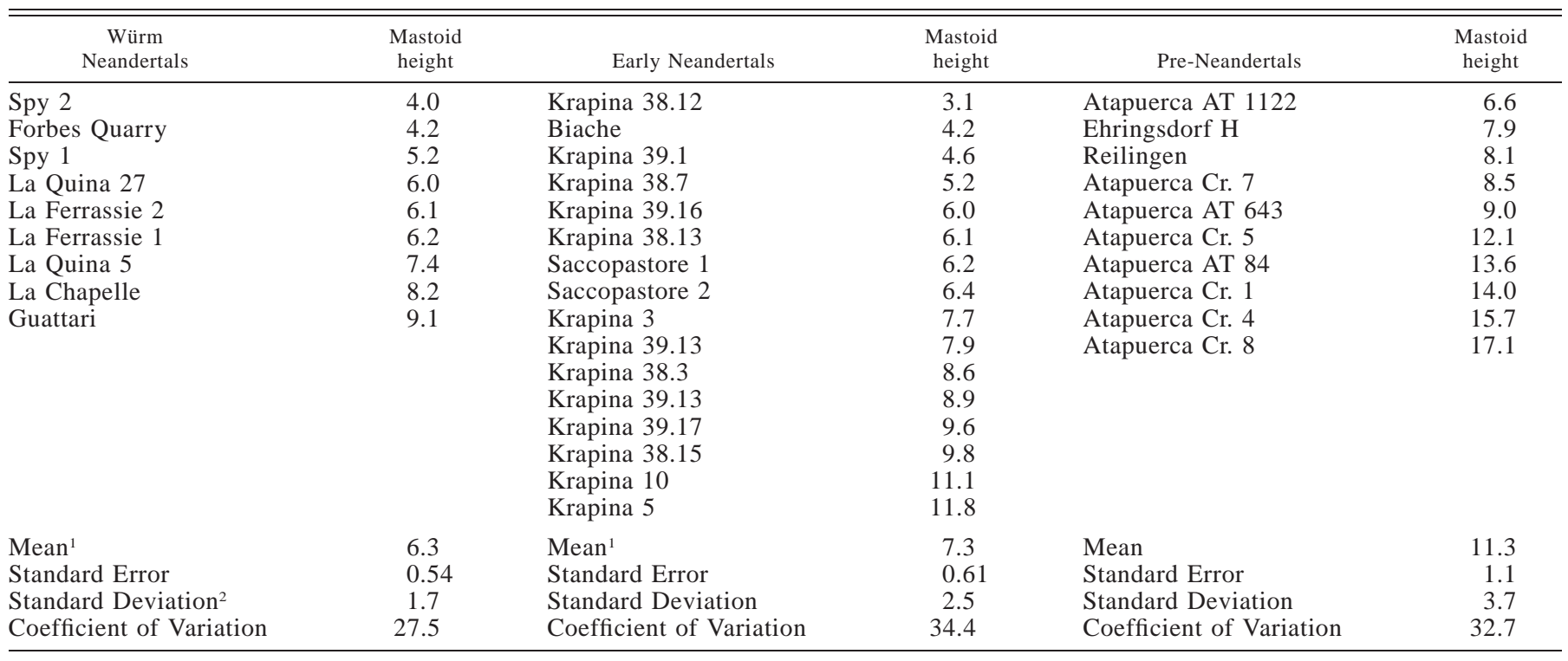

${ }^{1} \mathrm{~A}$ one sided $t$-test shows this mean differs significantly from the Pre-Neandertal mean with a significance of $P=0.01$.

${ }^{2}$ An $F$-test shows the variance differs significantly from the Pre-Neandertal variance with a significance of $P=0.05$.

Accretion model, however, it is reasonable to ask what more appropriate grouping we should have examined.

\section{Trait Selection}

We limited our examination to features that Dean et al. (1998), Rak et al. (1996), and/or Hublin (1998) propose to be unique or very frequent features of the Neandertals, because variation in these traits is explained by the Accretion model. We omitted traits with sample sizes too small for any determination of statistical significance in the comparisons. This selected sample is no less likely to exhibit evolutionary changes than other traits we might have chosen to examine, and the traits we examined are easily recognizable. We focused on features that could be quantified, rather than on discrete characters, in order to test the changes in means and in the magnitude of variation that the Accretion model requires, and to examine the conditions under which selection or drift could account for their change. Our features are not exhaustive, but were picked to maximize sample size and represent different parts of the cranium, face, and dentition. These include the height of the mastoid process below the digastric sulcus (the projection of the mastoid below the cranial base is minimal in Neandertals, Table 1), nasal breadth (large in Neandertals, Table 2), relatively and absolutely tall orbits (Table 3), flattening of the lambdoidal region (as expressed in the lambdoidal depression index, Table 4), foramen magnum elongation (Table 5), and relative maxillary incisor breadth (the lateral incisor is often as broad as or broader than the central one, Table 6). We also examined changes in cranial capacity (Table 7). Large cranial capacity is not distinctive in Neandertals to the exclusion of later humans, but important in subsequent discussion. Many authors contend its evolution, as revealed by the changes shown in Table 7, like the evolution of other features would have to be explained as a homoplasy if Neandertals were genetically isolated from other human populations, and therefore

TABLE 2. Nasal breadths of European hominids (in mm).

\begin{tabular}{|c|c|c|c|c|c|}
\hline $\begin{array}{c}\text { Würm } \\
\text { Neandertals }\end{array}$ & $\begin{array}{l}\text { Nasal } \\
\text { Breadth }\end{array}$ & Early Neandertals & $\begin{array}{c}\text { Nasal } \\
\text { Breadth }\end{array}$ & Pre-Neandertals & $\begin{array}{c}\text { Nasal } \\
\text { Breadth }\end{array}$ \\
\hline Vindija 259 & 26.2 & Montmaurin 4 & 27.5 & Arago 21 & 29.2 \\
\hline St. Césaire & 27.7 & Krapina 49 & 29.7 & Apidima 2 & 31.0 \\
\hline Vindija 225 & 28.5 & Krapina 3 & 30.0 & Steinheim & 31.6 \\
\hline Kůlna & 30.0 & Saccopastore 1 & 32.9 & Atapuerca AT 1100 & 32.0 \\
\hline La Chapelle & 33.2 & Saccopastore 2 & 33.7 & Castel del Guido & 32.0 \\
\hline Arcy-sur-Cure & 33.3 & & & Petralona & 36.4 \\
\hline La Ferrassie 1 & 34.0 & & & Atapuerca AT 767/963 & 37.0 \\
\hline Forbes Quarry & 34.1 & & & Atapuerca Cr. 5 & 38.5 \\
\hline Guattari & 35.1 & & & & \\
\hline Mean & 31.3 & Mean & 30.8 & Mean & 33.5 \\
\hline Standard Error & 1.1 & Standard Error & 1.1 & Standard Error & 1.2 \\
\hline Standard Deviation & 3.3 & Standard Deviation & 2.5 & Standard Deviation & 3.3 \\
\hline Coefficient of Variation & 10.4 & Coefficient of Variation & 8.2 & Coefficient of Variation & 10.0 \\
\hline
\end{tabular}


TABLE 3. Orbit shape $(100 \times$ Height/Breadth $)$.

\begin{tabular}{|c|c|c|c|c|c|c|c|c|}
\hline Würm Neandertals & $\begin{array}{l}\text { Height } \\
(\mathrm{mm})\end{array}$ & Index & Early Neandertals & $\begin{array}{c}\text { Height } \\
(\mathrm{mm})\end{array}$ & Index & Pre-Neandertals & $\begin{array}{l}\text { Height } \\
(\mathrm{mm})\end{array}$ & Index \\
\hline La Chapelle & 37.2 & 79.5 & Krapina 6 & 33.4 & 82.5 & Apidima 2 & 31.0 & 75.6 \\
\hline La Ferrassie & 35.5 & 80.0 & Saccopastore 2 & 36.9 & 82.6 & Petralona & 36.8 & 76.1 \\
\hline Gibraltar & 38.2 & 92.3 & Krapina 3 & 37 & 90.0 & Steinheim & 32.1 & 82.7 \\
\hline Mean $^{1}$ & $37.4^{1}$ & $84.6^{2}$ & Mean & 36.3 & $86.2^{1}$ & Mean & 33.2 & 78.6 \\
\hline Standard Error & 0.7 & 3.1 & Standard Error & 1.0 & 2.1 & Standard Error & 1.3 & 1.7 \\
\hline
\end{tabular}

${ }^{1}$ Differs from the Pre-Neandertal mean at $P=0.01$.

${ }^{2}$ The mean difference from the Pre-Neandertals is almost significant at $P=0.05$.

hold its variation to be an argument against isolation. Metric data were collected by one of the authors (MHW) on the original specimens, except for measurements of Ceprano (Ascenzi et al. 1996), Apidima (Coutselinis et al. 1991), and the Atapuerca crania (Arsuaga et al. 1997; Martínez-Labarga and Arsuaga 1997). The cranial capacities are from published sources.

\section{Computational Methods}

The mean and standard deviation for each character within each group of Europeans were estimated from the metric data. The worldwide mean during these time periods was also estimated, as the sample mean of all non-European specimens available, with the exception of those West Asian samples that have been considered to be Neandertals by some authors, notably the Shanidar hominids, Tabun 1, and Amud 1. The worldwide mean is therefore conservative, in that we excluded the European sample from it and all those specimens that have been suggested to have European affinities. Such conservatism is desirable considering that the European sample is relatively large compared to that from other regions, and its inclusion would likely shift the centroid closer to Europe. Interestingly, however, experimental inclusion of the West Asian specimens in the worldwide sample did not alter the results, because these specimens are apparently not specifically like Europeans for these metric characterisitics.

The lumping across timespans of the non-European sample is not ideal, but we followed it because of some significant sampling problems for non-Europeans during this time period. There have been significant difficulties in the dates of some of the non-European specimens. Both the relatively smaller sample size of this set of specimens and the fact that the dates of some individual specimens, such as the Ngandong hominids from Java, cannot be localized to within 200,000 years interfere both with our ability to divide the specimens into time periods and with our ability to recognize temporal trends in the data. Additionally, those specimens for which relatively accurate assessments of date do exist show a bias toward relatively more ancient specimens in some regions (East Asia) and relatively recent ones in others (West Asia), confounding the issues of temporal change with geographic variation. For these reasons, except as noted below, we assume that the non-European means did not change during the relevant time periods.

If changes in the non-European means did occur and rendered the European population more divergent during a time period than our estimate indicates, our assumption would be nonconservative because it would make the European population look more similar to the worldwide mean than it actually was. We checked for this possibility by looking for trends over time, as far as we could identify them, in the non-European sample. For many of the characters, including nasal breadth, foramen magnum shape, and orbit shape, the non-European specimens simply did not appear to change over time. However, in two cases, mastoid length and lambdoidal depression, the non-Europeans did appear to exhibit

TABLE 4. Lambdoidal depression index $(100 \times$ Lambda-inion chord/Biasterionic diameter $)$.

\begin{tabular}{|c|c|c|c|c|c|}
\hline Würm Neandertals & Index & Early Neandertals & Index & Pre-Neandertal & Index \\
\hline Spy 2 & 46 & La Chaise (Suard) 2 & 43 & Bilzingsleben & 36 \\
\hline Le Moustier & 48 & Saccopastore 1 & 47 & Vértesszöllös & 39 \\
\hline Guattari & 48 & Krapina 5 & 49 & Swanscombe & 48 \\
\hline Forbes Quarry & 48 & La Chaise (Delaunay) 17 & 50 & Ceprano & 48 \\
\hline Lebenstedt & 50 & Biache & 57 & Atapuerca Cr. 4 & 51 \\
\hline La Chapelle & 50 & & & Atapuerca Cr. 5 & 52 \\
\hline La Ferrassie 1 & 50 & & & Atapuerca Cr. 1 & 53 \\
\hline Spy 1 & 51 & & & Petralona & 53 \\
\hline La Quina 5 & 53 & & & Reilingen & 54 \\
\hline Mean & 49 & Mean & 49 & Mean & 48 \\
\hline Standard Error & 0.7 & Standard Error & 2.3 & Standard Error & 2.2 \\
\hline Standard Deviation ${ }^{1}$ & 2.1 & Standard Deviation & 5.1 & Standard Deviation & 6.5 \\
\hline Coefficient of Variation & 4.2 & Coefficient of Variation & 10.4 & Coefficient of Variation & 13.4 \\
\hline
\end{tabular}

${ }^{1}$ An $F$-test shows that variance of the Würm Neandertals differs significantly from the Early Neandertals and Pre-Neandertals at $P=0.01$. 
TABLE 5. Foramen magnum elongation (percent of breadth/length).

\begin{tabular}{lclc}
\hline \hline \multicolumn{1}{c}{$\begin{array}{c}\text { Würm and Early } \\
\text { Neandertals }\end{array}$} & $\begin{array}{c}\text { Rela- } \\
\text { tive } \\
\text { breadth }\end{array}$ & \multicolumn{1}{c}{ Pre-Neandertal } & $\begin{array}{c}\text { Rela- } \\
\text { tive } \\
\text { breadth }\end{array}$ \\
\hline La Chapelle & 68 & Atapuerca Cr. 4 & 71 \\
Gánovce & 69 & Swanscombe & 73 \\
Biache & 74 & Atapuerca Cr. 5 & 74 \\
La Ferrassie 1 & 77 & Petralona & 85 \\
Saccopastore 1 & 89 & & \\
Mean & 75 & Mean & 76 \\
Standard Error & 3.8 & Standard Error & 3.2 \\
Standard Deviation & 8.4 & Standard Deviation & 6.3 \\
Coefficient of Variation & 11.2 & Coefficient of Variation & 8.3 \\
\hline
\end{tabular}

${ }^{1}$ The Neandertal sample is too small to divide into Early and Würm groups, we consider them together because the foramen magnum should be relatively long in both according to the Accretion model.

a trend opposite in direction to the direction of change within Europe. In these two cases, the later group of non-Europeans was more different from later Europeans than was the overall non-European mean, and in these cases we tested explicitly against contemporary samples rather than across time periods. In only one of these characters, the degree of lambdoidal depression, did the trend in non-European specimens make a difference in the result, causing the sample mean of the Würm Neandertals to diverge from the sample non-European mean more than the expected amount, while it did not do so when compared to the full set of non-Europeans. For cranial capacity, the non-Europeans had a significant trend in the same direction as the Europeans, this resulted in later Europeans being more similar to later non-Europeans than to the overall non-European sample, as reported below.

With these data, the computation of our tests is quite straightforward. If the European phenotypic mean for a character is found to differ from the non-European mean by more than the $95 \%$ limit of the $\chi^{2}$ distribution, then the character is surprisingly divergent in the European population during that time period, assuming our evolutionary model is correct. If few characters are found to be surprising using these criteria, then our evolutionary model, the hypothesis of neutral evolution with gene flow, will not be rejected by this pro- cedure. The strength of this test depends on the accuracy of estimates of mean and standard deviation from the available data. Given the small sample sizes, the strength of the method is an appropriate concern, and we report the standard errors of all these estimates.

\section{RESULTS}

The results of the analysis are fairly unambiguous (Table 8). Of the 19 comparisons of groups, the sample mean of the European group was significantly different from the nonEuropean sample mean only four times. Each of these four represented a sample difference between European and nonEuropean groups that exceeded the $95 \%$ probability threshold of divergence, but these were the only four comparisons that did so, assuming that the heritability of the traits equals 0.5 . The rest of the comparisons yielded no significant difference between the European and non-European sample means, and even taking the differences at face value, the levels of difference between the samples were well within the range expected for a subpopulation with gene flow.

A finer temporal subsampling of the non-Europeans tends to make an additional comparison significant also, the lambdoidal depression in Würm Neandertals. However, such finer sampling renders the cranial capacity of the same group insignificant, so the overall result is unchanged. This same measurement is evaluated as divergent when compared to the entire set of non-Europeans if we disregard the lack of significant difference, under the assumption that heritability equals 0.25 , this being the only measurement where this assumption of lower heritability changes the result.

If these characters are indeed representative of the "distinctiveness" of the Pleistocene European population, then we must conclude that the population is surprisingly not "distinctive", at all. Instead, they are no farther from the worldwide phenotypic mean for most of these "distinctive", characters than would be expected for a random set of characters in a population connected to others by gene flow. These data clearly do not justify an interpretation of isolation or other special explanations to explain the evolution of people in this region.

TABLE 6. Relative maxillary incisor breadths of European hominids.

\begin{tabular}{|c|c|c|c|}
\hline Würm Neandertals & $\begin{array}{c}100 \times \mathrm{I}^{2} \text { breadth } \\
/ \mathrm{I}^{1} \text { breadth }\end{array}$ & Early Neandertals & $\begin{array}{c}100 \times \mathrm{I}^{2} \text { breadth } \\
/ \mathrm{I}^{1} \text { breadth }\end{array}$ \\
\hline Arcy-sur-Cure H1 & 94 & Krapina D18 & 92 \\
\hline Hortus 8 & 95 & Krapina D29 & 96 \\
\hline Teshik Tash & 96 & Krapina D17 & 97 \\
\hline La Quina 5 & 98 & La Chaise (Delaunay) 18 & 98 \\
\hline Genay & 100 & Krapina 46 & 98 \\
\hline Marillac & 100 & La Chaise (Delaunay) 9 & 101 \\
\hline St. Césaire & 101 & Krapina 48 & 102 \\
\hline La Ferrassie 2 & 102 & Ehringsdorf $\mathrm{G}$ & 102 \\
\hline Hortus 12 & 103 & Krapina 49 & 104 \\
\hline Le Moustier & 105 & Krapina 50 & 106 \\
\hline Hortus 7 & 105 & & \\
\hline Mean & $99.9^{1}$ & Mean & $99.6^{1}$ \\
\hline Standard Error & 1.1 & Standard Error & 1.3 \\
\hline Standard Deviation & 3.8 & Standard Deviation & 4.2 \\
\hline Coefficient of Variation & 3.8 & Coefficient of Variation & 4.2 \\
\hline
\end{tabular}

\footnotetext{
${ }^{1}$ Mean not significant to the nearest $10^{\text {th }}$, but presented to show slight difference between samples.
} 
TABLE 7. Cranial capacity for adult specimens of younger individuals old enough to have attained adult vault size (in cc).

\begin{tabular}{|c|c|c|c|c|c|}
\hline $\begin{array}{c}\text { Würm } \\
\text { Neandertals }\end{array}$ & $\begin{array}{c}\text { Cranial } \\
\text { capacity }\end{array}$ & Early Neandertals & $\begin{array}{l}\text { Cranial } \\
\text { capacity }\end{array}$ & Pre-Neandertal & $\begin{array}{l}\text { Cranial } \\
\text { capacity }\end{array}$ \\
\hline Forbes Quarry & 1270 & La Chaise (Suard) 1 & 1065 & Steinheim & 950 \\
\hline Spy 1 & 1305 & Krapina 3 & 1200 & Atapuerca Cr. 6 & 1100 \\
\hline La Quina 5 & 1367 & Saccopastore 1 & 1258 & Arago 21 & 1166 \\
\hline Feldhofer & 1525 & Saccopastore 2 & 1300 & Ceprano & 1185 \\
\hline Spy 2 & 1553 & Gánovce & 1320 & Petralona & 1220 \\
\hline \multirow{2}{*}{ La Ferrassie 1} & & & & Reilingen & 1430 \\
\hline & & & & Ehringsdorf $\mathrm{H}$ & 1450 \\
\hline Mean & 1494 & Mean $^{2}$ & 1242 & Mean $^{1}$ & 1240 \\
\hline Standard Error & 43 & Standard Error & 37 & Standard Error & 47 \\
\hline Standard Deviation & 129 & Standard Deviation & 97 & Standard Deviation & 155 \\
\hline Coefficient of Variation & 8.6 & Coefficient of Variation & 7.8 & Coefficient of Variation & 12.5 \\
\hline
\end{tabular}

${ }^{1}$ This value is a likely minimum.

${ }^{2}$ A t test shows this mean differs from the Würm Neandertal mean with a significance of $P=0.01$. None of the variances differ significantly.

\section{Do the Characters "Accrete"'?}

As we discuss the particular characters below, we caution that the observed changes in phenotype of these characters over time are obtained from a very small number of specimens. We describe changes in the characters here as an empirical exercise, because they make quite clear that the data, such as they are, do not support an intrepretation of "accretion" of unique character states over time in the European sequence. Where these patterns of change over time are statistically significant, we make explicit the level of statistical significance in the tables and in our description.

One character is an exception to the apparent pattern of similarity between Europeans and non-Europeans and might illuminate the process of character accretion, if it occurred. Two of the significantly divergent group comparisons occurred for the mastoid height from digastric sulcus. Importantly, these two comparisons were significantly divergent in opposite directions: the Pre-Neandertals were unusually tall compared to non-Europeans, whereas the Würm Neandertals were unusually short. An examination of only the non-European specimens closest in time to these groups increases the significance of the comparisons. Empirically, it would seem that an early European population that had significantly diverged from other populations evolved first to be more similar to them and then to assume the opposite condition. The change between Pre-Neandertal and later samples, which is statistically significant $(P<0.01)$ does not support the Accretion model, which predicts that earlier European populations should diverge with less magnitude than later $\mathrm{Eu}-$ ropeans, but in the same direction.

The Accretion model is also not supported by change in other characters. For example, the orbit shape index is less in Pre-Neandertals than the non-European mean, then increases significantly $(P<0.05)$ in Early Neandertals, and appears to decrease slightly, although not significantly, in Würm Neandertals in the direction of the non-European mean. This pattern of evolution clearly cannot be described as "accretion" in the sense of the Accretion model. Furthermore, unlike the first two characters, the remaining char- acters simply do not change significantly in Europe over time. Nasal breadth, lambdoidal depression, foramen magnum shape, and relative maxillary incisor breadth have no significant change in phenotype over time in the European sequence. This is strong evidence that the Accretion model does not provide an accurate account of evolutionary pattern in Europe.

\section{Level of Variation}

A second issue raised by the Accretion model is the level of phenotypic variation within European samples. Some researchers have examined the variance of metric features in Europe, expecting decreases in variance to be the result of genetic drift (e.g., Dean 1998; Hublin 1998; Maureille and Houet 1998). As we have noted above, this issue is not especially relevant to evolutionary pattern because genetic drift does not typically reduce phenotypic variance in an inbred subpopulation (Falconer and Mackay 1996). Nevertheless, the available data allow us to examine whether phenotypic variance decreased over time in Europe, and for most of these characters it did not. Orbit shape, nasal breadth, foramen magnum shape, and relative maxillary incisor breadth all show no significant change in variance between any time periods in Europe, and many of these appear to increase in variance over time rather than decrease. Only mastoid height and lambdoidal depression decrease significantly in variance over time between European samples. These two cases are interesting, because in both cases it is the reduced variation of Würm Neandertals that causes this group to differ significantly from the non-European mean, accounting for half the total cases of significant phenotypic divergence in Europe. The decreased variance of this group, which does not occur for other characters, would suggest that either selection or sample bias has given us a Würm sample with less than the expected amount of variance.

\section{Cranial Capacity}

Cranial capacity increases significantly within the European sample without a significant change in variability (Table 
TABLE 8. Results: Column 4 reports whether the sample means of European and non-European specimens are significantly different. Columns 6 and 8 report whether the level of difference between the sample means produces a $\chi^{2}$ greater than the $95 \%$ confidence threshold, which is 3.84 with one degree of freedom, with heritability of 0.5 and 0.25 , respectively.

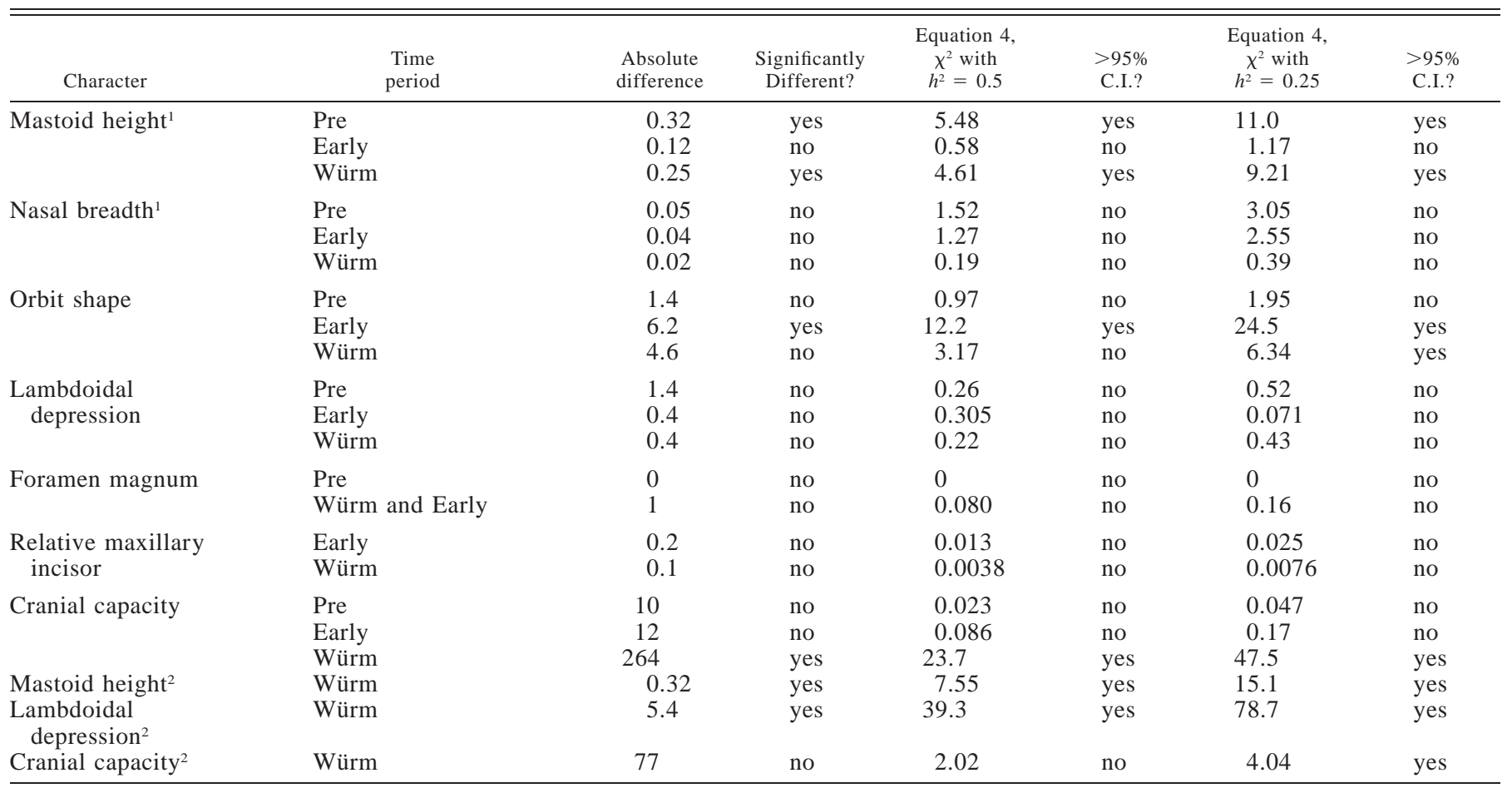

${ }^{1}$ Comparisons are made with ln-transformed data. This transform had no effect on the results.

${ }^{2}$ Comparisons made with later part of non-European sample only.

7). This increase results in the Würm Neandertals exhibiting a significant deviation from the overall non-European mean. Large cranial capacity, however, is not a Neandertal autapomorphy. It increases in the non-European sample over time also (Ruff et al. 1997), and its increase is usually and logically attributed to selection. This pattern of increase is fully consistent with a model of gene flow between these groups, as demonstrated by the non-significant difference between the Würm Neandertals and the Late Pleistocene subset of nonEuropean specimens (Table 8).

Cranial capacity evolution differs from the other characters in that we can show that it is guided by selection and not drift. Following Lande (1976) we examined the strength of

TABLE 9. Change ${ }^{1}$ for Neandertal cranial capacity (from Table 7).

\begin{tabular}{lcccc}
\hline \hline & \multicolumn{1}{c}{$\begin{array}{c}\text { t in } 25 \\
\text { year } \\
\text { genera- } \\
\text { Samples: }\end{array}$} & $\Delta(\bar{x}) / \sigma$ & $\begin{array}{c}\text { Minimum } \\
\text { selection }\end{array}$ & $N_{e}$ \\
\hline Early-Würm & 1.63 & 3400 & $1.5 \times 10^{-3}$ & $1.2 \times 10^{3}$ \\
Pre-Early & 0.06 & 6800 & $2.1 \times 10^{-5}$ & $1.8 \times 10^{6}$ \\
\hline
\end{tabular}

${ }^{1}$ Calculations as described in Lande (1976, equations 12 and 19), where the difference in means is given as the difference between the means of the $1 n$ transformed data, divided by the average standard deviation of these data. Selection calculated is the minimum selective mortality (proportion culled per generation) in the absence of drift assuming $h^{2}=0.5$, and the effective population size $\left(N_{e}\right)$ is the magnitude required for a $5 \%$ chance that a change at least as large as the observed change could be caused by drift in the complete absence of selection. Both drift and selection in a population connected to others by gene flow are possible explanations for the observed changes. selection and the minimum amount of genetic drift (measured by effective population size) necessary to explain the rate of change in cranial capacity among our European samples. These models are somewhat unrealistic because they assume no gene flow into Europe from elsewhere; we use it for illustration only. Examination of changes in cranial capacity under the drift hypothesis (based on data in Table 7) shows a pattern of $N_{e}$ variation that could be compatible with neutral genetic drift in Europe alone (Table 9), but this hypothesis is unlikely considering that the worldwide human population, with $N_{e}$ estimated at 10,000 to 20,000 individuals, appears to undergo approximately the same magnitude of change across the human range during the same time period (Ruff et al. 1997). Therefore drift is an unreasonable explanation. The strongest minimum pruning selection these changes require is on the order of $10^{-3}$, which seems entirely credible for evolutionary changes in cranial capacity in ancient humans.

Though Würm Neandertals do not differ from non-Europeans more than we would expect if the populations exchanged genes, this group is larger than their non-European contemporaries in cranial capacity. This increased size could have several consequences reflected in the anatomical changes discussed here. One of these may be in orbit height, which shows a nonsignificant increase that may reflect increasing cranial capacity, because these two features are related in humans (Schultz 1965). Another may be the projection of the mastoid process, suggested by the fact that whereas pro- 
jection below the digastric sulcus decreases over time in Europe (Table 1), the projection of the mastoid below the Frankfurt Horizontal remains the same, and is the same in living Europeans (Dean et al. 1998; Martínez-Labarga and Arsuaga 1997; Vallois 1969). The difference between samples probably reflects the posterior-inferior expansion of the cranial base that follows from the increased cranial capacity among Neandertals (Table 7). Therefore, we cannot reject the hypothesis that the significant divergences observed between some European groups and contemporary non-Europeans are related to differences in cranial capacity observed in later Europeans.

All these characters are fully consistent with a model of gene flow between Pleistocene Europeans and non-Europeans. The data give us no reason to believe that any significant isolation occurred among these groups. Recalling the important possibility that selection or environmental variance may have influenced changes in any of these traits, we may question whether the data demonstrate Europeans to be particularly distinctive at all. It is certain that the hypothesis of gene flow is not refuted.

\section{DisCUSSION}

Obviously we would prefer to have a larger sample of fossil hominids to examine questions of gene flow, but we can only work with the sample at hand and accept its limitations. The Accretion model that we have addressed must depend on the same sample and, of course, has the same limitations. One could argue that the constraints imposed by the sample make any statement of evolutionary model imprecise to the point where it risks invalidity, and we sympathize with this view. Nonetheless, the Accretion model has been widely published and accepted as an explanatory hypothesis, and we cling to the simple principle that if there is sufficient reason to believe a hypothesis, there must be sufficient data to test it.

Given that the very data that have been used to generate the Accretion model apparently provide no support for it, we must wonder why the model exists. The reason is an artifact of the history of anthropology. The Accretion model is a variant of polygenism, much like the pseudo-evolutionary model proposed by Coon (1962) in which human subspecies were thought to have evolved in parallel, in virtual or complete isolation from each other. Today, no one contends that living human groups have independent origins early in the Pleistocene. But polygenism has been resurrected by scientists who assert that such separate origins do in fact exist: evolution in isolation for recent human groups in the Late Pleistocene (discussed by Templeton 1998), and separate origins for ancient human groups in the Early Pleistocene, delineated for archaic Europeans by the Accretion model.

The key feature of pseudo-evolutionary polygenism is its reliance on massive parallelism to explain evolutionary trends shared by different groups. When researchers describe the phylogeny of our genus in terms of a 'bush' of hominid species during the past two million years, usually unstated is the fact that whenever this " bushlike" pattern is subjected to phylogenetic analysis, hefty levels of homoplasy are the necessary result. Such homoplasy can be explained under this hypothesis only by the interpretation that any long-term evo- lutionary trends are parallel developments in separated genetic systems. Even explanations of behavioral evolution have come to require parallelism to account for what can be readily observed in the archaeological record (Mellars 1989). As archaeologists grapple with the questions of how and where modern human behaviors arose in the Late Pleistocene, the fact that they appear in European Neandertals and subSaharan Africans at about the same time also requires that modern human behaviors evolved independently and in parallel (Zilhão and D'Errico 1999), for those who assume that Neandertals are a different species.

The Accretion model, as a descriptive hypothesis, does not make explicit whether distinct lineages or separate demes within a single species are thought to underlie this pattern, but neither of these can resolve the problems raised by the underlying polygenic interpretation. Limiting our investigations to crania, the subject of this paper, the foremost evolutionary trend among all representatives of Pleistocene Homo is the expansion of brain size, but others include:

(1) reduction in the cranial superstructures (central and lateral supraorbital and nuchal tori) and in cranial bone thickness; (2) expansion of the occipital plane of the occiput at the expense of the nuchal (muscle-bearing) plane; (3) expansion of the superciliary aspect of the supraorbital torus, while the lateral structures reduce and in some cases degenerate; (4) anterior dental reduction; and (5) nasal breadth reduction.

Any account of evolution within our genus must explain these facts. The only explanation provided by the Accretion model and other polygenic variants is parallelism.

At the extreme, Tattersall (1996, p. 52) defends an interpretation of multiple contemporary Homo species in the Pleistocene and explains the parallel evolutionary trends this interpretation requires as follows:

"Natural selection takes place at the level of the local population, and in similar circumstances closely related populations are likely to respond to ecological pressures or other agents of natural selection upon them in similar ways. These various considerations will hold true even when such local populations have become individual evolutionary entities. When, that is, speciation has intervened between them.',

It is of interest to compare this with Wiley's (1981, p. 25) definition of the evolutionary species: "a single lineage of ancestral-descendant populations which maintains its identity from other lineages and which has its own evolutionary tendencies and historical fate.' It is plain that if Tattersall is correct then the evolutionary species definition must be invalid, because different closely related species might be expected to have the same evolutionary tendencies. Alternatively, if the definition is valid and provides a means of comparing present and past species, then Tattersall is incorrect in presuming that a number of the same long-term evolutionary trends can take place in different species (especially in the human case; Wolpoff 1994), when the purported species are wide-ranging and contiguous. We prefer the second alternative as by far a more likely, and more testable, proposition. Parallelism does occur in evolution and is more com- 
mon among closely related species than among distantly related groups. However, the level of parallelism required to support a "bushlike" interpretation of our evolution is insupportable, when compared to the more parsimonious alternative of gene flow among groups. There is no scientific basis for any polygenic theory of human evolution (Wolpoff and Caspari 1997).

By directly testing the hypothesis of gene flow among these ancient groups, we provide a novel way to address the ancestry of recent humans. Rogers (1995) points out the difficulty of testing the hypothesis of replacement of ancient humans isolated within regions with humans of geographically separate origins. However, the polygenic model based on replacement depends not only on the wholesale migration of recent humans from a single source, but also on the complete isolation of archaic humans before this dispersal event. The demonstration that we cannot substantiate any isolation between ancient regions directly weakens the hypothesis of replacement by showing that the geographic source population for recent humans, in the genetic sense, must extend across more than one ancient region of the world. Even if substantial migrations occurred during the Late Pleistocene, the genetic background of this expanding population reflects a prior equilibrium population with migration from several regions. This genetic continuity should be considered by researchers who compare recent and ancient groups. Our analysis suggests strongly that the observations of Relethford (1995), who examines the differences of recent human groups in terms of an equilibrium migration model with much larger population size in Africa than in other regions, provide an appropriate basis for understanding the genetic differentiation of recent and ancient humans.

In summary, our study demonstrates clearly that no special explanations or phenomena are required to account for the evolution of certain characters in Pleistocene Europeans that have been described as "distinctive"' in this population. The hypothesis that this population was connected to other populations by gene flow during the Pleistocene has not been rejected by morphological evidence. This finding is consistent with molecular evidence from ancient DNA sequence variation, which shows a higher divergence between Neandertals and recent humans than among recent humans alone, but a threefold lower divergence than would be expected if these groups had diverged before the Late Pleistocene (Krings et al. 1997, 1999). It is also consistent with morphological evidence for genetic exchanges between Europeans and other populations after 40,000 years ago (Frayer 1993). A simple and homogeneous model of gene flow at levels equal to recent humans between populations of unchanging sizes is without doubt too simple to fully describe the evolution of Pleistocene humans. We have every reason to believe that different human populations have experienced different selective, environmental, and demographic histories. Nevertheless, using the currently available data, as slim as they are in places, we are able to say with confidence that the morphological differences present between Neandertals and other populations are not the result of complete isolation of Europe from other regions. They do not have to be attributed to the genetic isolation of a unique Neandertal lineage. They are compatible with an antiparallelist explanation of selection and genic ex- changes, and the results of isolation by distance across the broad range of territories occupied by the human speciesin other words, Multiregional evolution.

\section{ACKNOWLEDGMENTS}

We thank the curators of the fossil Neandertal remains that we examined for permission to study the specimens in their care. We are grateful to K. Rosenberg, E. Trinkaus, and an anonymous reviewer for helpful comments and suggestions.

\section{Literature Cited}

Arsuaga, J. L., I. Martinez, A. Gracia, and C. Lorenzo. 1997. The Sima de los Huesos crania (Sierra de Atapuerca, Spain). A comparative study. J. Hum. Evol. 33:219-281.

Ascenzi, A., I. Biddittu, P. F. Cassoli, A. G. Sergi, and E. SergiNaldini. 1996. A calvarium of late Homo erectus from Ceprano, Italy. J. Hum. Evol. 31:409-424.

Coon, C. S. 1962. The origin of races. Knopf, New York.

Coutselinis, A., C. Dritsas, and T. Pitsios. 1991. Expertise médicolégale du crâne Pléistocène LA01/S2 (Apidima II), Apidima, Laconie, Grèce. L'Anthropol. 95:401-408.

Dean, D., J-J. Hublin, R. Holloway, and R. Ziegler. 1998. On the phylogenetic position of the pre-Neandertal specimen from Reilingen, Germany. J. Hum. Evol. 34:485-508.

Falconer, D. S., and T. F. C. Mackay. 1996. Introduction to quantitative genetics. 4th ed. Longman, Essex, U.K.

Frayer, D. W. 1993. Evolution at the European edge: Neanderthal and Upper Paleolithic relationships. Préhistoire Européenne 2: 9-69.

Harpending, S., M. A. Batzer, M. Gurven, L. B. Jorde, A. R. Rogers, and S. T. Sherry. 1998. Genetic traces of ancient demography. Proc. Natl. Acad. Sci. USA 95:1961-1967.

Hawks, J., S-H. Lee, K. Hunley, and M. Wolpoff. 2000. Population bottlenecks and Pleistocene human evolution. Mol. Biol. Evol. $17: 2-22$.

Howell, F. C. 1952. Pleistocene glacial ecology and the evolution of "classic Neandertal" man. Southwest J. Anthropol. 8: $377-410$.

Hublin, J-J. 1998. Climatic changes, paleogeography, and the evolution of the Neandertals. Pp. 295-310 in T. Akazawa, K. Aoki, and O. Bar-Yosef, eds. Neandertals and modern humans in Western Asia. Plenum, New York.

- 2000. Modern-nonmodern hominid interactions: a Mediterranean perspective. Pp. 157-182 in O. Bar-Yosef and D. Pilbeam, eds. The geography of Neandertals and modern humans in Europe and the greater Mediterranean. Peabody Museum of Archaeology and Ethnology, Harvard University, Cambridge, MA. Bulletin no. 8.

Krings, M., A. Stone, R. Schmitz, H. Krainitzid, M. Stoneking, and S. Pääbo. 1997. Neandertal DNA sequences and the origin of modern humans. Cell 90:1-20.

Krings, M., H. Heisert, R. W. Schmitz, H. Krainitzki, and S. Pääbo. 1999. DNA sequence of the mitochondrial hypervariable region II from the Neandertal type specimen. Proc. Natl. Acad. Sci. USA 96:5581-5585.

Lande, R. 1976. Natural selection and random genetic drift in phenotypic evolution. Evolution 30:314-334.

_ 1979. Quantitative genetic analysis of multivariate evolution, applied to brain:body size allometry. Evolution 33: 402-416.

Løfsvold, D. 1988. Quantitative genetics of morphological differentiation in Peromyscus. II. Analysis of selection and drift. Evolution 42:54-67.

Martínez-Labarga, C., and J. L. Arsuaga. 1997. The temporal bones from Sima de los Huesos Middle Pleistocene site (Sierra de Atapuerca, Spain). A phylogenetic approach. J. Hum. Evol. 33: 283-318.

Maureille, B., and F. Houet. 1998. La variabilité morpho-métrique 
du nez: dérive génique dans la lignée Neandertalienne? Biometr. Hum. Anthropol. 16:27-33.

Mellars, P. A. 1989. Major issues in the emergence of modern humans. Curr. Anthropol. 30:349-385.

Parés, J. M., A. Pérez-González, A. B. Weil, and J-L. Arsuaga. 2000. On the age of the hominid fossils at the Sima de los Huesos, Sierra de Atapuerca, Spain: paleomagnetic evidence. Am. J. Phys. Anthropol. 111:451-461.

Rak, Y., W. H. Kimbel, and E. Hovers 1996. On Neandertal autapomorphies discernible in Neandertal infants: a response to Creed-Miles et al. J. Hum. Evol. 30:155-158.

Relethford, J. H. 1995. Genetics and modern human origins. Evol. Anthropol. 4:53-63.

Rogers, A. R. 1995. How much can fossils tell us about regional continuity? Curr. Anthropol. 36:674-676.

Rogers, A. R., and H. C. Harpending. 1983. Population structure and quantitative characters. Genetics 105:985-1002.

Ruff, C. B., E. Trinkaus, and T. W. Holliday. 1997. Body mass and encephalization in Pleistocene Homo. Nature 387:173-176.

Schultz, A. H. 1965. The cranial capacity and orbital volume of hominoids according to age and sex. Homenaje a Juan Comas en su 65 Anniversario, 2. Libros de Mexico, Mexico City.

Stringer, C. B., and J-J. Hublin 1999. New age estimates for the Swanscombe hominid and their significance for human evolution. J. Hum. Evol 37:873-877.
Tattersall, I. 1996. Paleoanthropology and preconception. Pp. 4754 in W. E. Meikle, F. C. Howell, and N. G. Jablonski, eds. Contemporary issues in human evolution. Wattis Symposium Series in Anthropology, Calif. Acad. Sci. Mem. no. 21.

Templeton, A. 1998. Human races: a genetic and evolutionary perspective. Am. Anthropol. 100:632-650.

Trinkaus, E. 1992. Paleontological perspectives on Neanderthal behavior. Pp. 151-176 in M. Toussaint (ed): 5 Millions d'Années, l'Adventure Humaine. Étud. Recher. Archéol. l'Université Liège no. 56.

Vallois, H. V. 1969. Le Temporal Néandertalien H 27 de La Quina. Anthropologie. 73:365-400, 525-544.

Wiley, E. O. 1981. Phylogenetics: the theory and practice of phylogenetic systematics. John Wiley and Sons, New York.

Wolpoff, M. H. 1994. What does it mean to be human-and why does it matter? Evol. Anthropol. 3:116-117. 1999. Paleoanthropology. 2d ed. McGraw-Hill, New York.

Wolpoff, M. H., and R. Caspari. 1997. Race and human evolution. Simon and Schuster, New York.

Wright, S. 1951. The genetical structure of populations. Ann. Eugen. 15:323-354.

Zilhão, J., and F. D'Errico 1999. The chronology and taphonomy of the earliest Aurignacian and its implications for the understanding of Neandertal extinction. J. World Prehist. 13:1-68.

Corresponding Editor: E. Brodie III 